\title{
Compliance and Psychological Impact of Quarantine in Children and Adolescents due to Covid-19 Pandemic
}

\author{
Kumar Saurabh $^{1} \cdot$ Shilpi Ranjan ${ }^{2}$ (I) \\ Received: 18 April 2020 / Accepted: 11 May 2020 / Published online: 29 May 2020 \\ (C) Dr. K C Chaudhuri Foundation 2020
}

\begin{abstract}
Objectives To examine a cohort of children and adolescents quarantined during Coronavirus disease 2019 outbreak in India and to describe their understanding of, compliance with and the psychological impact of quarantine experience.

Methods One hundred twenty one children and adolescents along with their parents were interviewed regarding their compliance and psychological distress during the quarantine period. A comparable data was also obtained from 131 children and adolescents who were not quarantined.

Results Most of the children and adolescents were non-compliant as compliance with all requirements was low (7.43\%), though compliance with community protective measures $(17.35 \%)$ was better than compliance with household protective measures $(10.71 \%)$. Quarantined children and adolescents experienced greater psychological distress than non-quarantined children and adolescents $(\mathrm{p}<0.001)$. Worry $(68.59 \%)$, helplessness $(66.11 \%)$ and fear $(61.98 \%)$ were the most common feelings experienced under quarantine.

Conclusions The low compliance with quarantine requirements as seen in this study raises a serious concern about the effectiveness of quarantine as a preventive measure of disease transmission. Compliance and mental health problems can be improved by providing adequate financial support and enhanced knowledge about pandemic planning.
\end{abstract}

Keywords Adolescents · Compliance · Quarantine · Psychological · Covid-19

\section{Introduction}

Quarantine is the separation and restriction of movement of people who have potentially been exposed to a contagious disease. The primary purpose of quarantine is to prevent transmission of an infectious agent from those potentially incubating it. Persons are usually quarantined in their homes but they may also be quarantined in community based facilities [1]. The scientific use of quarantine was began by United Kingdom in response to Plague, but this word was first used by Venice, Italy in 1127 with regard to Leprosy [2]. Most recently quarantine has been widely used worldwide as a tool to prevent transmission of coronavirus disease 2019 (Covid-19).

Shilpi Ranjan

dr_saurabh_life@yahoo.com

1 Department of Pediatrics, Government Medical College, Bettiah, Bihar, India

2 Department of Community Medicine, Nalanda Medical College and Hospital, Patna, Bihar, India
India is using quarantine as a tool to fight Covid-19 since the first case of Covid-19 was diagnosed in January 2020. In view of rising number of cases, Government of India imposed nationwide lockdown since 25th March 2020 to break the transmission chain [3]. With the enforcement of lockdown, a very large number of migrant workers from cities along with their families started to return back to their homes. Such susceptible and exposed individuals may act as super-spreaders at their native places. As it will be difficult to track them and their contacts, Ministry of Health and Family Welfare, in its advisory directed them to be placed under quarantine at their respective states, either at home or at quarantine centres for $14 \mathrm{~d}$ since the last exposure [4]. The quarantine requirements following exposure to Covid-19 were designed to minimise transmission to the community as well as to protect household members.

For normal psychological development and wellbeing of children, companionship and social interaction is an essential component. There is an increased risk of psychiatric disorders whenever there is separation of children from their caregivers $[5,6]$. More importantly, the age of initial separation is known 
to be relevant to psychological development [7]. It has been realised that quarantine like measures might have adverse psychological effect on children.

There are many articles which compare adult and healthcare workers under quarantined to those who were not quarantined. But there are very few comparable studies on children and adolescents regarding their quarantine experiences, especially from India. This study describes understanding, compliance and psychological impact of quarantine on children and adolescents in the age group of $9 \mathrm{y}$ to $18 \mathrm{y}$ during Covid-19 outbreak.

\section{Material and Methods}

During Covid-19 outbreak, Ministry of Health and Family Welfare released its guidelines regarding quarantine at home and at facilities /centres. Local public health units were responsible for identification and quarantine of contacts of potential Covid-19 cases. Complying with the Government order, all persons placed under quarantine were to be provided with mask, thermometer (if necessary) and instructions about quarantine requirements. These supplies were to be delivered to the individual's residence or at quarantine centres. All quarantined adolescents were to undergo daily medical examination for appearance of symptoms suggestive of Covid-19. Quarantined persons were encouraged to remain in contact with their family members through phone to avoid anxiety $[1,4]$.

Children and adolescents in the age range of $9 \mathrm{y}$ to $18 \mathrm{y}$ who were placed either at home quarantine or facility quarantine, who remained well and were followed by healthcare workers after discharge from quarantine centres, were included in the study. With these criteria, 121 children and adolescents were eligible to participate. Comparable groups were taken from the neighbourhood of quarantined children and adolescents with the same family background (Number = 131). All children and adolescents were attending either government or private school before this period. Children and adolescents were interviewed in detail along with their parents regarding their knowledge of quarantine facility, compliance during quarantine and psychological effect of quarantine. This interview was based on a preformed questionnaire which assessed adolescents' understanding of rationale of quarantine, quarantine behaviors as well as socioeconomic and psychological impacts. During quarantine, required behaviors included mask usage, living in separate room with door closed and restriction of activities designed to prevent Covid-19 transmission to the household and to the community.

Ethical approval was taken from the institute's Ethics committee. Written informed consent was taken from children and their parents. In statistical methods, first descriptive analysis was done which includes frequency, percent, mean and standard deviation. Student's $t$ test for continuous variables and Pearson's Chi square test for categorical variables were used to compare quarantined and non-quarantined groups. Level of significance was set at $p<0.05$. Data entry and statistical analysis were performed using the Statistical Package for Social Science (SPSS) version 26.0.

\section{Results}

The age range of children and adolescents was between $9 \mathrm{y}$ to $18 \mathrm{y}$ with a mean age of $15.4 \mathrm{y}$. Most of the adolescents were males $(85.12 \%)$. Thirty seven $(30.57 \%)$ were quarantined at home and rest $(77.68 \%)$ at quarantine centres.

Most adolescents (73.55\%) identified correctly that quarantine had been imposed to protect the community, whereas only $51.23 \%$ of adolescents understood that the use of quarantine restrictions was also to protect members of the household. Less than half $(44.63 \%)$ reported that quarantine would not protect themselves. Only $16.52 \%$ of adolescents were able to understand all rationale based questions (Table 1). Compliance with quarantine behavior varied from $25.61 \%$ (slept in a separate room by themselves) to $92.56 \%$ (did not go out to socialise). The proportion of adolescents who adhered and were compliant with all the household protective measures was only $10.71 \%(N=13)$, whereas compliance with all the community protecting measures combined was higher $(17.35 \%)$. When compliance to all the behaviors was taken as a whole, it reduced to $7.43 \%$ only. It means only $9(7.43 \%)$ children and adolescents were correctly following all the instructions related to quarantine. The most difficult $(65.26 \%)$ activity for children and adolescents to comply with was not going out of the house to socialise (to visit friends and relatives).

This study also assessed qualitative indicators (feelings) of psychological impact associated with quarantine. Worry (68.59\%), helplessness $(66.11 \%)$ and fear $(61.98 \%)$ were the most common feelings experienced during quarantine. Children and adolescents who were under quarantine had statistically significant more psychological problems than those who were not quarantined. Fear $(\mathrm{p}<0.0001)$, nervousness ( $\mathrm{p}$ $<0.0001)$ and annoyance ( $\mathrm{p}<0.001)$ were most significantly seen in the quarantined group. Anxiety related insomnia, isolation, boredom (not statistically significant) and sadness was also more common in the quarantine group.

When asked in detail, these high levels of psychological problems like worry, helplessness and fear were mainly associated with loss of father's job, financial losses of family and unavailability of basic life needs. Some children and adolescents were concerned about infecting others whereas a few thought that they had Covid-19 $(p<0.05)$. It was very surprising that children and adolescents who were quarantined felt that people reacted differently to them than the nonquarantined group with statistically significant difference $(p$ 
Table 1 Understanding the rationale, compliance and difficulties associated with quarantine among adolescents and children

\begin{tabular}{lll} 
1. Understanding of rationale for quarantine & Number (n) 121 & Percentage (\%) \\
1a. Quarantine protects self & 67 & 55.37 \\
1b. Quarantine protects household & 62 & 51.23 \\
1c. Quarantine protects community & 89 & 73.55 \\
1d. All correct & 20 & 16.52 \\
Compliance & & \\
2. Compliant with all household protective measures & 13 & 10.71 \\
2a. Used separate towels & 41 & 33.88 \\
2b. Used separate plates for eating & 39 & 32.23 \\
2c. Slept in separate room & 31 & 25.61 \\
2d. Used mask when family members present & 31 & 25.61 \\
3. Compliant with all community protective measures & 21 & 17.35 \\
3a. Did not go out of house to socialise & 112 & 92.56 \\
3b. Did not run errands outside of home & 101 & 83.47 \\
3c. Used mask for home healthcare visits & 51 & 42.14 \\
3d. Used mask when answer door & 48 & 39.66 \\
3e. Did not allow visitors into home & 81 & 66.94 \\
4. Compliant with all protective measures & & 7.43 \\
5. Most common difficulties & 9 & 65.26 \\
5a. Not going out of house to socialise & 79 & 64.46 \\
5b. Not going out of house to errands & 78 & 58.67 \\
5c. Using mask when family member present & 71 & 48.76 \\
5d. Staying in room by self with door closed & & \\
\hline & &
\end{tabular}

$<0.0001)$. These children and adolescents also avoided people having fever and cough $(\mathrm{p}<0.05)$.

\section{Discussion}

Pandemics, like other disasters, have been a part of human history for centuries. However, response to pandemics necessarily differs as it requires separation, isolation and quarantine. Beyond the potential community protective effects attributed to quarantine, the risk to quarantined individuals needs to be identified [8].

This study in children and adolescents raises important concerns regarding the effectiveness and applicability of quarantine in recent era. Ministry of Health and Family Welfare of India directed in its advisory that asymptomatic contacts of potential Covid-19 patients were required to remain in quarantine for $14 \mathrm{~d}$ after their last exposure $[1,4]$. It is obvious that implementation of quarantine for preventing transmission at community level will be only effective when we adhere to its compliance. But there are many limitations of such hypothetical agreement of quarantine adherence. As this study shows, compliance with all requirements was as low as $7.43 \%$, indicating that quarantine in its present form would be of limited value in controlling transmission. Family members were at a higher risk since the compliance was only $17.35 \%$. Compliance in relation to preventing community transmission was significantly higher $(17.35 \%)$ than household transmission (10.71\%). As a whole, most of the children and adolescents were non-compliant, potentially putting their family and community at risk. Results of present study in relation to compliance of quarantine requirements are lower than the previous studies $[9,10]$. Unfortunately almost half were supposing that they were protecting themselves in quarantine (Table 1).

Here it is observed that there remains a significant chance of improvement in compliance. This can be achieved by improved knowledge about the disease and a better understanding of quarantine measures. A previous study reported that when asked about specific problems related to quarantine, the two most frequently cited "major" problems were emotional difficulties related to the confinement and not getting paid because they had to miss their duty [9]. In the present study the most common difficulty for children and adolescents was not going out to socialise.

Children who were quarantined at facility/centre might be more susceptible to mental health problems than children who were quarantined at home because of their higher risk of infection and fear caused by parental separation [11, 12], however, the authors did not analyse these relationship in their study. So beyond the potential community protecting effects attributed to quarantine, the risk of quarantined children needs to be identified. 
The consistency of the psychological problem in children and adolescents is very high in the present study group. In this study, most (around 68\%) of quarantined children showed some or other form of psychological distress which is much higher than the non-quarantined group with statistically significant difference in most of the feelings (Table 2). Other studies related to psychological impact in quarantined adults generally reported a high prevalence of symptoms of psychological distress like the present study. These studies reported emotional disturbance, depression, stress, low mood, irritability, insomnia, posttraumatic stress symptoms, anger and emotional exhaustion. Quarantine studies also found a range of other feelings such as, confusion, fear, anger, grief, numbness and anxiety related insomnia $[8,9,13,14]$. A study on children also found that the mean post-traumatic stress scores were four times higher in children who had been quarantined to those who were not quarantined [8]. Long term behavior changes after the quarantine period, such as vigilant hand washing and avoidance of crowds have been reported [15].

However, point to be noted here is that non-quarantined children also show a higher level of stress during Covid-19 period. Previous studies from India have reported psychological distress in 13 to $45 \%$ of school children and adolescents [16, 17]. Higher level of psychological problems in these children can be attributed to restriction of activity, school closure and confinement at home due to nationwide lockdown. So, this study also provides comparable data of psychological impact of pandemic within the non-quarantined group.

The distribution of different feelings and emotions in this study matches with previous studies $[8,9]$ though frequency of worry, helplessness and fear was much higher in the present study. On detailed interview, the authors found that children and their parents were more concerned about financial loss, loss of father's job, future uncertainties and unavailability of daily needs like food and water. Here, most children were related to families of migrant workers. Thus, socioeconomic and financial status of parents also has a significant role as a stressor in quarantine period. Financial loss, as a result of quarantine was found to be a risk factor for symptoms of psychological disorders, anger and anxiety $[18,19]$.

Although great efforts have been made by the Government of India across country, it is almost impossible to provide psychological interventions nationwide because most local support focuses only on meeting basic needs of children. In
Table 2 Comparison of psychological impact among quarantined and non-quarantined adolescents

\begin{tabular}{|c|c|c|c|}
\hline & $\begin{array}{l}\text { Quarantined } \\
N=121(\%)\end{array}$ & $\begin{array}{l}\text { Non- } \\
\text { quarantined } \\
N=131(\%)\end{array}$ & $P$ value \\
\hline \multicolumn{4}{|l|}{ Feelings } \\
\hline Worry & $83(68.59)$ & $68(51.90)$ & 0.0069 \\
\hline Helplessness & $80(66.11)$ & $63(48.09)$ & 0.0039 \\
\hline Fear & $75(61.98)$ & $43(32.82)$ & 0.00001 \\
\hline Nervousness & $73(60.33)$ & $40(30.53)$ & 0.00001 \\
\hline Anger & $71(58.67)$ & $60(45.80)$ & 0.040 \\
\hline Annoyance & $70(57.85)$ & $46(35.11)$ & 0.00029 \\
\hline Loneliness & $59(48.76)$ & $35(26.71)$ & 0.0003 \\
\hline Boredom & $48(39.66)$ & $50(38.16)$ & 0.89 \\
\hline Isolation & $46(38.01)$ & $34(25.95)$ & 0.039 \\
\hline Frustration & $40(33.05)$ & $38(31.40)$ & 0.48 \\
\hline Sadness & $31(25.61)$ & $28(21.37)$ & 0.42 \\
\hline Insomnia & $29(22.13)$ & $18(13.74)$ & 0.03 \\
\hline Confusion & $25(20.66)$ & $23(17.55)$ & 0.53 \\
\hline \multicolumn{4}{|l|}{ Covid-19 Concerns } \\
\hline Know someone hospitalised or died & $26(21.48)$ & $17(12.97)$ & 0.72 \\
\hline Concerned about infecting others & $18(14.87)$ & $17(12.97)$ & 0.66 \\
\hline Thought had Covid-19 & $11(9.09)$ & $3(2.29)$ & 0.018 \\
\hline \multicolumn{4}{|l|}{ Behavior after Quarantine } \\
\hline Avoided people with Fever and cough & $49(40.49)$ & $31(23.66)$ & 0.004 \\
\hline Avoided crowded places & $31(25.61)$ & $28(21.37)$ & 0.42 \\
\hline Avoided public places & $22(18.18)$ & $21(16.03)$ & 0.08 \\
\hline People reacted differently & $46(38.01)$ & $11(8.39)$ & 0.00001 \\
\hline
\end{tabular}


one study, inadequate basic supplies like food, water and clothes during quarantine was a source of frustration, anxiety and anger even after four to 6 mo after release [18]. To minimise the psychological effects we should increase children's access to disease information via comic books and videos and timely referral to psychiatrist. Social media could play an important role, allowing people who are quarantined to update their loved ones about themselves. So, having a working mobile phone is now a necessity, not a luxury.

There are several limitations of this study. The sample size was small but it included wide range of adolescent age group. Socioeconomic details such as education and household income were not collected in the comparable group which could be helpful in planning future requirements in respect to quarantine. Furthermore, analysis of the quarantined household members and household composition was not done. This study relies on children's, adolescents' and their parents' retrospective perception of feelings and behaviors associated with stressful experiences which could be flawed due to recall bias and social desirability.

In conclusion, this study suggests that understanding, compliance and knowledge regarding quarantine behavior is poor in the reported group; also the psychological impact of quarantine is wide ranging and substantial. Quarantine, in its present form, requires further research to its utility for assessing transmission of Covid-19 especially in a resource-limited country like ours. Revised requirements, improved preparation along with collaborative network of psychiatrists, psychotherapists, researchers and community volunteers can minimise the psychological impact of quarantine experiences.

Authors' Contributions Both the authors contributed to the concept, data analysis, drafting, literature review, critical revision and approval of the manuscript. SK will act as Guarantor for this paper.

\section{Compliance with Ethical Standards}

Ethical Approval The study was approved by Institutional ethics committee.

\section{Conflict of Interest None.}

Consent Written informed consent was taken from participants.

\section{References}

1. MOHFW. Guidelines for Quarantine Facilities COVID-19- NCDC. Available at: https://ncdc.gov.in $>$ WriteRe...PDF guidelines For Quarantine facilities COVID-19-NCDC. Accessed 16 April 2020.
2. Newman K. Shutt up: Bubonic plague and quarantine in early modern England. J Sol Hist. 2012;45:809-34.

3. Wikipedia. India Lockdown. Available at: https:/en.wikipedia.org/ wiki/2020_coronavirus_lockdown_in_India. Accessed 16 April 2020.

4. MoHFW. Advisory for Quarantine of Migrant Workers. Available at: https://www.mohfw.gov.in/pdf/Advisoryforquarantineofmigrantworkers. pdf. Accessed 16 April 2020.

5. WHO. The importance of caregiver-child interactions for the survival and healthy development of young children: A review. Geneva: World Health Organization; 2004.

6. Norredam M, Nellums L, Nielsen RS, Byberg S, Petersen JH. Incidence of psychiatric disorders among accompanied and unaccompanied asylum seeking children in Denmark: A nation-wide register-based cohort study. Eur Child Adoles Psy. 2018;27:43946.

7. Humphreys KL. Future directions in the study and treatment of parent child separation. J Clin Child Adolesc Psychol. 2019;48: 166-78.

8. Sprang G, Silman M. Posttraumatic stress disorder in parents and youth after health-related disasters. Disaster Med Public Health Prep. 2013;7:105-10.

9. Reynolds DL, Garay JR, Deamond SL, Moran MK, Gold W, Styra R. Understanding, compliance and psychological impact of the SARS quarantine experience. Epidemiol Infect. 2008;136:9971007.

10. Blendon RJ, Benson JM, DesRoches CM, Raleigh E, Taylor-Clark $\mathrm{K}$. The public's response to severe acute respiratory syndrome in Toronto and the United States. Clin Infect Dis. 2004;38:925-31.

11. Wang G, Zhang Y, Zhao J, Zhang J, Jiang F. Mitigate the effects of home confinement on children during the COVID-19 outbreak. Lancet. 2020;395:945-7.

12. Liu JJ, Bao Y, Huang X, Shi J, Lu L. Mental health considerations for children quarantined because of COVID-19. Lancet. 2020;4: 347-9. https://doi.org/10.1016/S2352-4642(20)30096-1.

13. DiGiovanni C, Conley J, Chiu D, Zaborski J. Factors influencing compliance with quarantine in Toronto during the 2003 SARS outbreak. Biosecur Bioterror. 2004;2:265-72.

14. Lee S, Chan LY, Chau AM, Kwok KP, Kleinman A. The experience of SARS-related stigma at Amoy gardens. Soc Sci Med. 2005;61:2038-46.

15. Cava MA, Fay KE, Beanlands HJ, McCay EA, Wignall R. The experience of quarantine for individuals affected by SARS in Toronto. Public Health Nurs. 2005;22:398-406.

16. Kumar V, Talwar R. Determinants of psychological stress and suicide behaviour in Indian adolescents: A literature review. J Indian Assoc Child Adolesc Ment Health. 2014;10:47-68.

17. Bhad P, Awasthi A, Passi GR. Relationship of leisure time activities and psychological distress in school children. Indian Pediatr. 2019;56:686-8.

18. Jeong H, Yim HW, Song Y-J, et al. Mental health status of people isolated due to Middle East respiratory syndrome. Epidemiol Health. 2016;38:e2016048.

19. Mihashi M, Otsubo Y, Yinjuan X, Nagatomi K, Hoshiko M, Ishitake T. Predictive factors of psychological disorder development during recovery following SARS outbreak. Health Psychol. 2009;28:91-100.

Publisher's Note Springer Nature remains neutral with regard to jurisdictional claims in published maps and institutional affiliations. 